\title{
EXPERIMENTOS EM GENÉTICA E BIOQUÍMICA: MOTIVAÇÃO E APRENDIZADO EM ALUNOS DO ENSINO MÉDIO DE UMA ESCOLA PÚBLICA DO ESTADO DO MARANHÃO
}

\section{EXPERIMENTS IN GENETICS AND BIOCHEMISTRY: MOTIVATION AND LEARNING IN HIGH SCHOOL STUDENTS FROM A PUBLIC SCHOOL IN MARANHÃO STATE.}

\author{
Priscila Marlys Sá Rivas ${ }^{1}$; Jaqueline Diniz Pinho² ${ }^{2}$ Sérgio Luis Araújo Brenha ${ }^{3}$ \\ ${ }^{1}$ Estudante de Ciências Biológicas, Universidade Federal do Maranhão. \\ ${ }^{2}$ Graduada em Ciências Biológicas, Universidade Federal do Maranhão. \\ ${ }^{3}$ Professor do Departamento de Biologia, Universidade Federal do Maranhão.
}

\section{RESUMO}

Este trabalho teve por objetivo introduzir no Colégio Universitário da Universidade Federal do Maranhão um conjunto de aulas práticas para o entendimento de Genética e Bioquímica. O planejamento das aulas práticas baseou-se nos Parâmetros Curriculares Nacionais. Oito atividades experimentais foram executadas no laboratório do colégio. Através de questionários aplicados aos alunos foram avaliados o impacto das metodologias empregadas e os conhecimentos adquiridos. Os questionários foram apurados e os resultados expressos em porcentagem. A maioria dos alunos afirmou que a metodologia empregada foi de fácil entendimento $(93,75 \%)$ e que as práticas aumentaram sua motivação para o aprendizado de genética e bioquímica $(82,50 \%)$. Verificou-se um aumento no número de acertos após as práticas e uma mudança na natureza das respostas (diminuição das questões em branco e das incorretas). Evidenciou-se o efeito benéfico de aulas práticas sobre o aprendizado e motivação de estudantes do ensino médio da rede pública.

Palavras-chave: Experimentos, ensino médio, genética, bioquímica, aprendizado.

\begin{abstract}
This study aimed to introduce in the College of the Federal University of Maranhão a set of practical experiments for the understanding of genetics and biochemistry. The planning of the practical classes was based on the National Curricular Parameters. Practical lessons were performed in the college's laboratory and were eight experimental activities. Questionnaires were applied to students and the impact of methodologies and knowledge gained were assessed. The questionnaires were counted and the results expressed in percentages. Most students believe that the method was easy to understand $(93.75 \%)$ and the practices have increased their motivation for learning genetics and biochemistry $(82.50 \%)$. There was an increase in the right answers number after practices and a change in the wrong responses nature (decrease of blanks and incorrects answers). Our results indicate the beneficial effect of practical lessons on learning and motivation of high school students from public schools.
\end{abstract}

Key-words: Experiments, secondary education, genetics, biochemistry, learning. 


\section{INTRODUÇÃ̃O}

Muitos professores discursam sobre a necessidade de implantação de práticas para o ensino de ciências, entretanto a maioria encontra dificuldades para materializar tais noções em sala de aula. Dentre os empecilhos estão o tempo, a má remuneração, que comprometem até mesmo a qualidade do ensino (CERRI \& TOMAZELLO, 2008).

Sabe-se que as atividades práticas ou experimentais estimulam o processo de ensino-aprendizagem. Porém, estas não devem ser vistas como uma comprovação da teoria dada em sala de aula e sim devem possibilitar a investigação, despertando a motivação e estimulando os estudantes a pesquisar sobre o porquê dos resultados observados (ISQUIERDO et al., 1999).

Desta forma, a prática pode ser uma aliada para o ensino de ciências, cuja construção dos conhecimentos depende da experimentação (SONCINI, 1985). Elas contribuem para o aprendizado dos métodos científicos, indicando aos alunos como desenvolver e executar etapas que permitam solucionar problemas e justificar, ou não, hipóteses pré-concebidas (LUNETTA, 1991). Além disso, as práticas servem como estratégia complementar para construção de uma nova visão sobre o tema abordado na teoria (LEITE et al., 2008).

A biologia, tal como as demais ciências, baseia-se em experimentação. Entretanto, observa-se uma heterogeneidade nas áreas de abrangência, englobando desde botânica, paleontologia, evolução até zoologia e genética. Por isso, é necessário o emprego de estratégias pedagógicas diferentes, principalmente em relação às aulas práticas.

A genética é o ramo da biologia que estuda os aspectos da hereditariedade, ou seja, os mecanismos pelos quais as características são transmitidas de pais para filhos. Atualmente o campo da Genética tem destaque entre as ciências de ponta do mundo e acumula avanços científicos notáveis, que vão desde o descobrimento da dupla hélice do DNA, por Watson e Crick (1953) até o sequenciamento total do Genoma Humano (2003). Porém, esta importância contrasta com a realidade observada em inúmeras escolas brasileiras. Pesquisas demonstraram que a maioria dos estudantes de ensino médio não sabia localizar na célula qual a região onde o material genético é encontrado, evidenciando uma deficiência no entendimento de uma informação básica (JUSTINA \& RIPPEL, 2003).

A genética é matéria integrante da grade curricular do ensino médio, e infelizmente é lecionada quase totalmente por meio de aulas expositivas, que limitam o 
entendimento e as fontes de pesquisa (REIS et al., 2010). Além disso, a maioria dos exemplos empregados nos materiais didáticos explora situações distantes da realidade dos estudantes. Estes fatos juntamente com a dificuldade natural de compreensão da genética acabam contribuindo para o desinteresse e desestímulo dos alunos por essa matéria tão importante.

Sabendo que a maioria dos alunos de escolas públicas do estado não tem acesso a aulas práticas e que as aulas práticas são um meio simples e eficaz de facilitar o aprendizado dos alunos, esse trabalho teve por objetivo introduzir no Colégio Universitário da Universidade Federal do Maranhão (COLUN-UFMA) um conjunto de aulas práticas para facilitar o aprendizado de Genética e Bioquímica.

\section{MATERIAIS E MÉTODOS}

\section{Planejamento das atividades experimentais}

O planejamento das aulas práticas tomou por base os Parâmetros Nacionais Curriculares e as Orientações Curriculares para o Ensino Médio (BRASIL, 1999; 2006). As práticas foram escolhidas de acordo com a sua aplicabilidade, facilidade de execução e disponibilidade dos materiais necessários.

\section{Atividades experimentais realizadas}

As aulas práticas de genética e bioquímica foram realizadas no laboratório do Colégio Universitário da UFMA (COLUN-UFMA), no período de 22 a 30 de novembro de 2010, tendo como público alunos do ensino médio.

As aulas práticas iniciavam com a demonstração do experimento por parte do professor. Os alunos eram, posteriormente, divididos em grupos para executar os experimentos. Os resultados obtidos eram anotados para discussão e análise, realizada no dia seguinte antes da nova aula prática. Ao total, foram realizadas oito atividades experimentais, sendo 04 de genética e 04 de bioquímica:

\section{Extração do DNA da banana}

Com este experimento pretendeu-se caracterizar o ácido desoxirribonucléico, entendendo os passos que resultaram na retirada do material genético do núcleo.

\section{Replicação, Transcrição e Tradução (ao vivo)}

Esta dinâmica objetivou elucidar os mecanismos de replicação, transcrição e tradução utilizando os alunos do curso como nucleotídeos ou aminoácidos.

\section{Determinação do sistema $A B O$}


Com esta prática visou-se relacionar genótipo ao fenótipo através da determinação dos grupos sanguíneos do sistema $\mathrm{ABO}$, assim como caracterizar as reações de aglutinação.

4 Teste de paternidade

Com a dinâmica aplicada visou-se transmitir os princípios e técnicas utilizadas para realização do teste de paternidade.

5 Caracterização de carboidratos

Este experimento simples objetivou caracterizar os carboidratos presentes nos tubérculos de batata inglesa, através da reação com alfa-naftol.

\section{Caracterização do amido da batata}

Com este experimento pretendeu-se caracterizar o amido presente nos tubérculos de batata inglesa através da reação com lugol (iodeto de potássio).

\section{Caracterização de proteínas do ovo e leite}

Objetivou-se com este experimento detectar a presença de proteínas presentes no ovo e no leite através da reação de Biureto.

\section{Desnaturação das proteínas do leite}

O último experimento realizado permitiu verificar macroscopicamente os efeitos da desnaturação de proteínas, utilizando como modelo experimental o leite.

\section{Avaliação dos conhecimentos adquiridos}

No primeiro dia do minicurso aplicou-se um questionário onde se perguntava sobre conceitos básicos de genética e bioquímica (ANEXO A), cuja finalidade era verificar o nível de conhecimento dos alunos interessados pelo curso. No último dia do minicurso, o mesmo questionário foi aplicado, para mensurar a evolução de cada aluno com as aulas práticas. Os questionários foram corrigidos, e as respostas foram classificadas quanto a sua natureza em: 1) Em branco; 2) Incorretas; 3) Incompletas relacionadas; 4) Corretas. Os questionários de avaliação do curso foram apurados e os resultados expressos em porcentagem.

Os gráficos expondo os resultados dos questionários foram confeccionados no programa GraphPad Prism 5.0. O teste de Teste de Mann-Whitney foi utilizado para verificar diferenças estatisticamente significante entre a porcentagem de acertos obtidos antes e após as aulas práticas. 


\section{Avaliação da metodologia}

A avaliação do impacto da metodologia aplicada foi feita através da aplicação de um questionário (ANEXO B) a cada aluno participante, com a intenção de sondar a opinião dos mesmos sobre a aplicação e entendimento das práticas, assim como sua satisfação e motivação. Os questionários foram apurados e os resultados expressos em porcentagem.

\section{RESULTADOS E DISCUSSÃO}

\section{Perfil dos alunos participantes}

As práticas foram aplicadas para um total de 25 alunos, a maioria do $3^{\circ}$ ano do ensino médio. No COLUN-UFMA há três turmas do terceiro ano do ensino médio, totalizando aproximadamente 120 alunos. O interesse a participar das aulas práticas surgiu em uma pequena parcela $(21 \%)$ do total de alunos do último ano do ensino médio, o que pode ser atribuído, em parte, a que esses alunos já estudaram a matéria de genética. É importante destacar que $84 \%$ dos alunos interessados era do sexo feminino e a faixa etária média era de 17,2 $\pm 0,8$ anos.

\section{Resultados obtidos e discussão dos experimentos}

No primeiro experimento, os alunos foram divididos em grupos de 04 para a execução dos experimentos. Realizou-se a extração do DNA da banana e os grupos obtiveram como resultado o pH final da solução de 4 e 5 (sem imagem), conforme o esperado, uma vez que o DNA é um ácido nucléico, e não um ácido forte. A discussão dos resultados abordou a estrutura e localização da molécula de DNA, assim como suas funções celulares nos organismos vivos.

No segundo experimento, todos os alunos participaram ativamente da construção da nova dupla fita do DNA na replicação, assim como na síntese do RNA na transcrição e do polipetídeo na síntese proteica, indicando as enzimas que atuam em cada uma das etapas (Figura 01). A discussão envolveu a explicação dos mecanismos de síntese proteica, temática um pouco abstrata para muitos estudantes do ensino médio.

No terceiro experimento, somente os voluntários serviram de cobaia para determinação do seu tipo sanguíneo pelo sistema ABO. Os resultados observados foram que a maioria dos voluntários possuía o tipo sanguíneo O (7 alunos), seguido do tipo A (4 alunos), B (2 alunos) e AB (1 aluno) (Figura 02). A discussão envolveu aspectos genéticos na determinação dos grupos sanguíneos, as transfusões sanguíneas, reações de aglutinação, sobre o sistema Rh e a doença hemolítica do recém-nascido. 
No quarto experimento, a técnica empregada para o teste de paternidade foi explicada pelos professores e atividade prática consistiu em desvendar o pai da criança através do padrão de bandas de DNA.
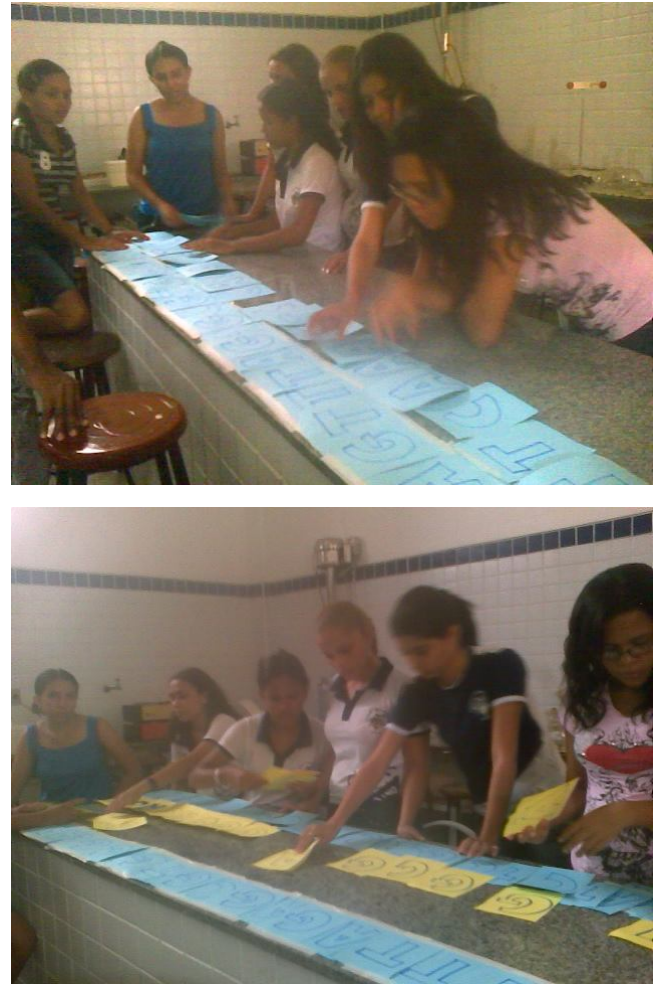

Figura 01 - Alunos durante a execução da aula prática sobre Replicação, Transcrição e Tradução ao vivo.
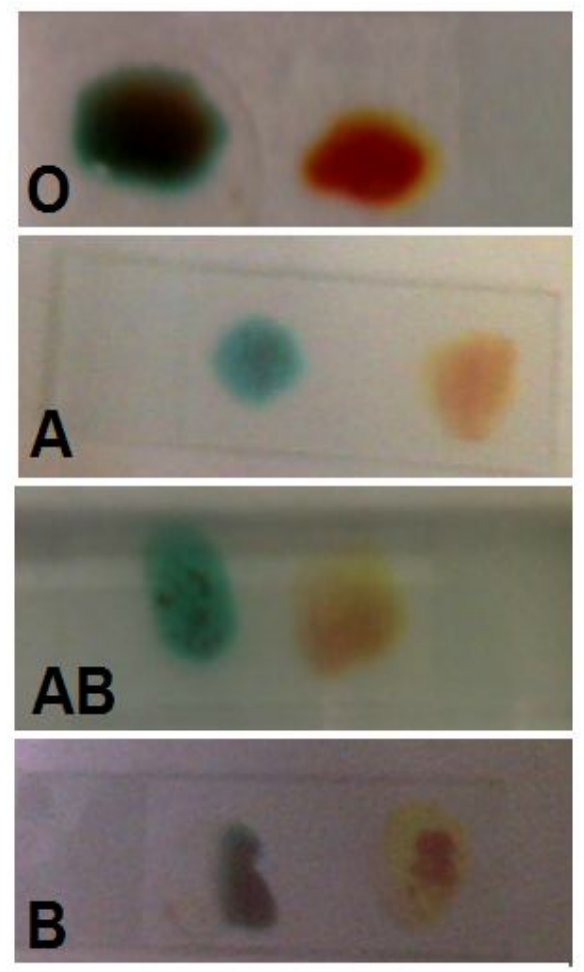

Figura 02 - Resultados observados parra a determinação do sistema $\mathrm{ABO}$ dos alunos.

Apesar da simplicidade da prática, esta foi uma das que contou com maior tempo de discussão, talvez porque o teste de paternidade é uma ferramenta da engenharia genética que vem sendo amplamente utilizada na resolução de casos judiciais e divulgada na mídia, sendo familiar aos alunos.

O quinto experimento foi o primeiro dos experimentos em bioquímica. Realizou-se o teste de Molish em três grupos de alunos e verificou-se que o extrato de amido contém carboidratos, pois houve a formação do anel roxo (Figura 03). A temática discutida abordou a estrutura química dos carboidratos, assim como sua classificação e função nos organismos vivos.

O sexto experimento, realizado com o extrato de batata foi para determinação do amido por reação de lugol. Nos resultados, observou-se que no tubo 1, que continha a solução de amido, processou-se reação determinado por coloração azul. Nos demais tubos 2 (açúcar) e 3 (água) não ocorreram reações, demonstrando que o lugol reage 
especificamente com o amido (Figura 04). Discutiu-se sobre os polissacarídeos e suas funções biológicas e fisiológicas.

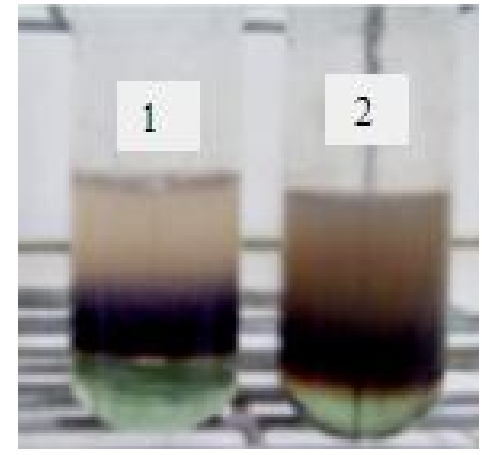

Figura 03 - Resultados da prática de determinação de carboidratos.

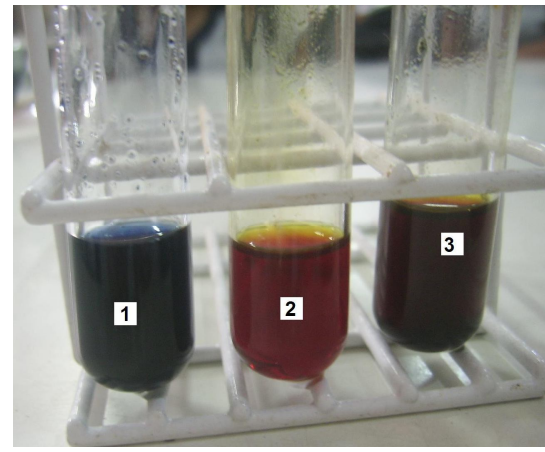

Figura 04 - Resultados da caracterização do amido por reação com lugol.

O experimento sete que visou caracterizar as proteínas do leite e do ovo por adição de Reativo de Biureto. Verificou-se que houve uma forte reação com a solução de albumina (tubo 1 - coloração roxa), não houve reação com a solução de amido (tubo 2 - transparente) e houve fraca reação com o leite (tubo 3 - coloração rosa), concluindose portanto que há maior quantidade de proteínas no ovo e posteriormente no leite. Também concluiu-se que no extrato de batata, não há proteínas devido a não reação com o Biureto (Figura 05). Discutiu-se sobre as proteínas, sobre sua composição: estrutura química e classificação dos aminoácidos que compõem as proteínas.

O oitavo e último experimento visou mostrar o que ocorre após desnaturação de proteínas do leite com a adição de ácido acético. Os resultados observados foram que houve a formação de um precipitado de coloração branca, indicando que com a mudança do pH da solução do leite, as proteínas dissolvidas mudaram sua conformação e não ficaram mais solúveis na solução, por isso formou-se o precipitado (Figura 06). A temática discutida abrangeu a estrutura química das proteínas, assim como os fatores capazes de modificar a estrutura das mesmas. Além disso, comentou-se sobre as fontes de proteínas na alimentação humana e suas funções nos organismos vivos. 


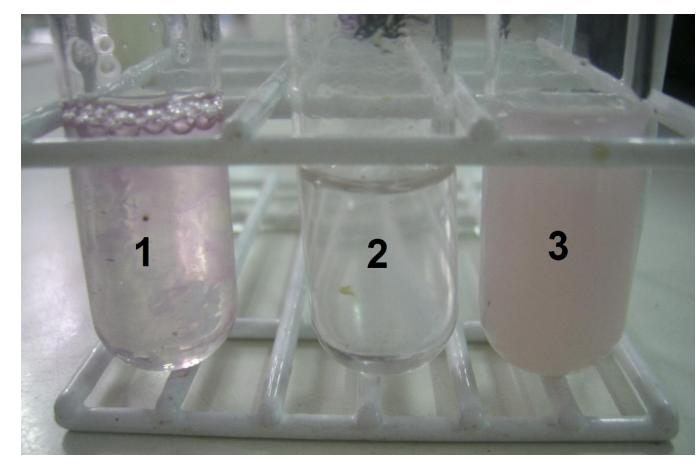

Figura 05 - Caracterização de proteínas do ovo e leite pela Reação de Biureto.

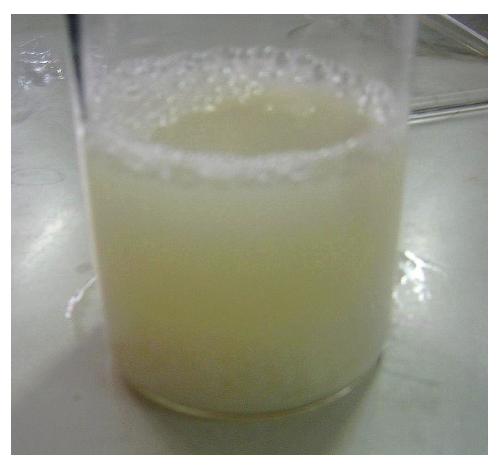

Figura 06 - Desnaturação de proteínas do leite com adição de ácido acético.

As aulas práticas, quando realizadas no ambiente de laboratório, parecem despertar a curiosidade e o interesse dos alunos, uma vez que a estrutura facilita a compreensão de fenômenos estudados em aulas teóricas. A positividade deste ambiente deve-se, em parte, à maior participação dos alunos na montagem dos experimentos e na interação com os resultados observados, mas também a maior informalidade, que contrasta com a monótona sala de aula (BORGES, 2002).

A subutilização dos laboratórios é frequentemente observada nas escolas, muitas vezes por ausência de material, equipamentos ou espaço adequado (GIOPPO et al., 1998). Entretanto, segundo o trabalho de Possobom (2003) a situação pode ser facilmente contornada com a utilização de materiais de baixo custo e adaptação à infraestrutura disponível, de forma a tornar este ambiente apto para a experimentação, proporcionando maior aprendizado, motivação e interação dos alunos com as ciências (POSSOBOM, 2003).

A prática e a teoria se complementam, principalmente no ensino de Biologia. As práticas permitem que alunos construam uma nova visão sobre o tema abordado na teoria (LEITE et al., 2008). As discussões realizadas após cada aula prática evidenciaram a importância desta complementariedade, pois assim os alunos puderam associar o que já haviam estudado na teoria com os resultados observados. Desta forma, as aulas práticas também possuem outra finalidade, a de demonstrar que a teoria dada em sala de aula possui aplicações concretas no cotidiano, mesmo sendo este raramente relatado pela maior parte dos professores. 


\section{Avaliação dos conhecimentos adquiridos}

Após a aplicação dos questionários sobre os conceitos básicos de genética antes das aulas práticas, os alunos acertaram, em média, 23,33 $\pm 2,71 \%$ das questões. Após as aulas práticas do minicurso, verificou-se um aumento significativo no número de acertos, que totalizaram 36,67 $\pm 3,8 \%$ das questões totais (Figura 07).

Além disso, a natureza das respostas foi modificada após as práticas. Em média, os alunos deixavam 5 questões em branco, respondiam 5 questões de forma incorreta, cerca de 4 questões de forma incompleta (mas com conteúdo relacionado) e somente 1 questão de forma correta. Após os experimentos, o número de questões deixadas em branco diminuiu para 3 , assim como as incorretas. O número de questões respondidas com conteúdo relacionado aumentou para 6 , assim como as corretas, que aumentou para 3, em média (Figura 08).

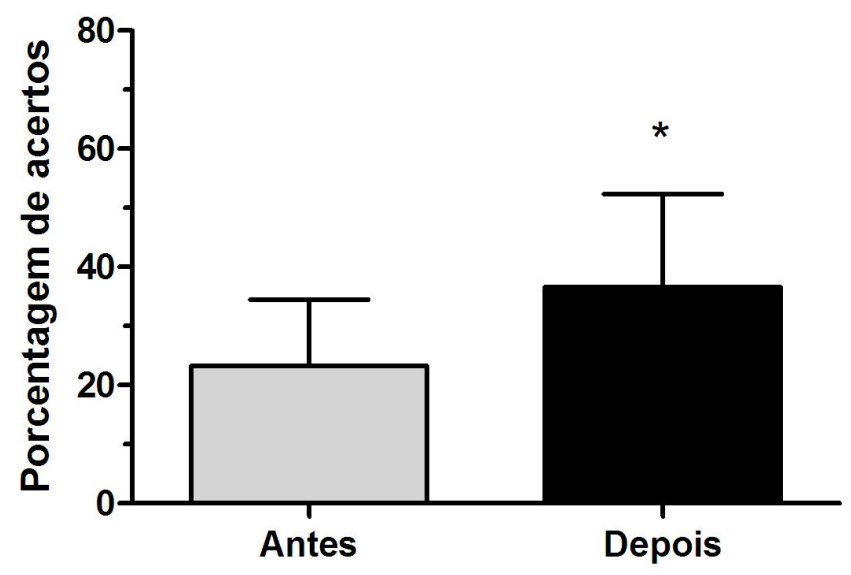

Figura 07 - Porcentagem de acertos antes e depois os experimentos de genética e bioquímica ministrados no COLUN-UFMA. As médias foram significativamente diferentes após Teste de Mann-Whitney (*p=0.011 e U=70.5). 


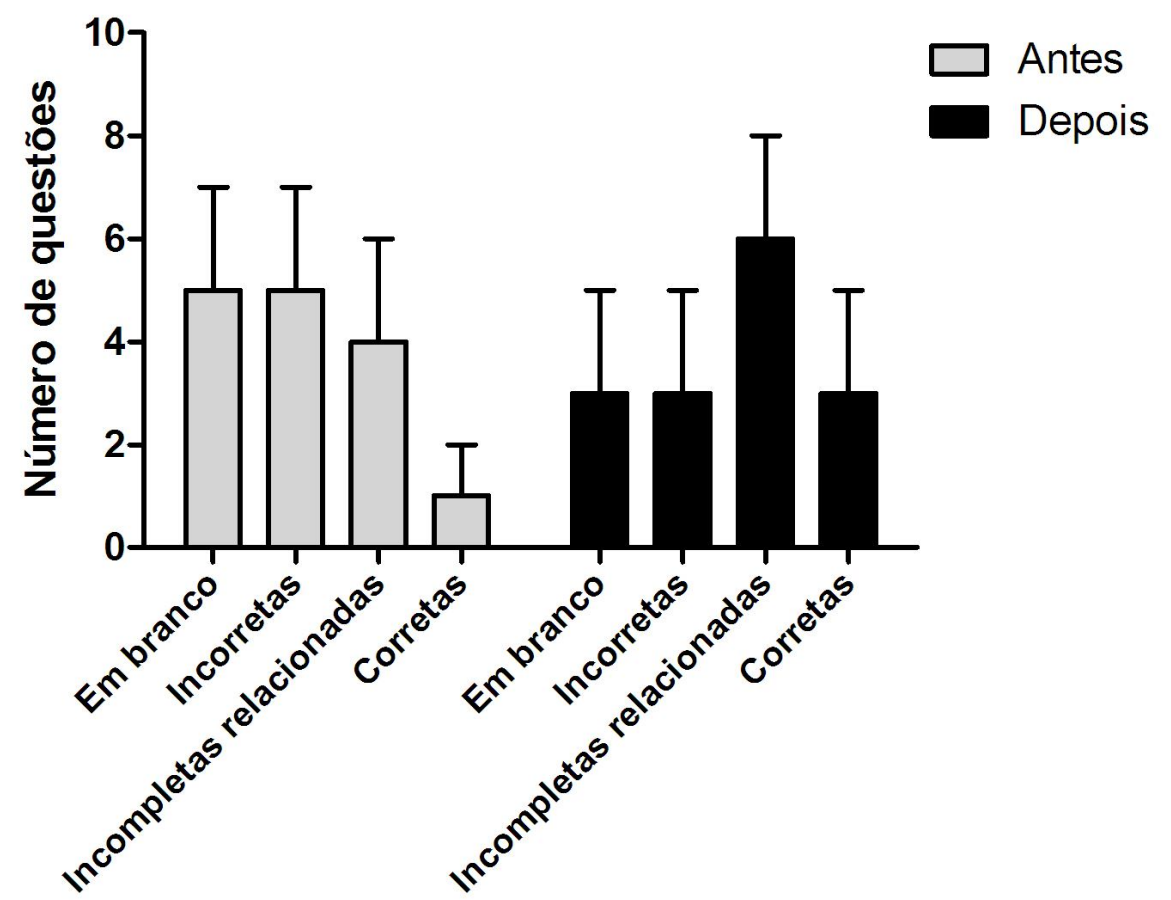

Figura 08 - Natureza das respostas dos alunos e antes e depois dos experimentos de genética e bioquímica ministrados no COLUN-UFMA.

O aumento no número médio de acertos (Figura 07) ressalta a clara efetividade do curso prático para o aprendizado. A diminuição das respostas incorretas e brancas (Figura 08) demonstra a que os alunos percebem o assunto das questões não como algo que desconhecido, o que aumenta a confiança para respondê-las. Os dados demonstram que o curso prático, teve sim, efeito positivo sobre o aprendizado dos alunos.

Fala e colaboradores (2010) verificaram em um trabalho semelhante que, após aulas práticas com Drosophila melanogaster e diversos cruzamentos experimentais, os alunos aumentaram o entendimento sobre genética mendeliana e determinação sexual, demonstrando que as aulas práticas melhoram a compreensão dos conteúdos teóricos.

Nunes e colaboradores (2006) introduziram aulas extraclasse de genética em escolas estaduais do interior de São Paulo e verificaram um grande envolvimento de alunos e professores do ensino médio e fundamental, destacado, também pela melhoria na aprendizagem.

A melhoria no aprendizado observada com a integração de atividades práticas com a teoria é uma abordagem antiga, que já é bem relatada na literatura. Neste tipo de metodologia, os alunos são os que constroem seu aprendizado, partindo de uma dúvida inicial, criando hipóteses. Seguem, então para a experimentação, observando os 
resultados e chegando a conclusões concretas. Por isso, a prática para o ensino de ciências é uma forma de desenvolver o "pensar científico", tão útil para a construção do conhecimento em diversas áreas. (LAKATOS, 2001).

\section{Avaliação da metodologia empregada nas práticas}

As respostas obtidas na avaliação (Tabela 1) demonstram que a maioria dos alunos $(93,75 \%)$ acreditam que as práticas foram de fácil aplicação. Concordaram também que, as aulas práticas ministradas apresentaram uma boa integração com o conteúdo teórico $(75 \%)$. A maioria afirmou que as metodologias empregadas foram de fácil entendimento $(93,75 \%)$ e que as práticas aumentaram sua motivação para o aprendizado de genética e bioquímica $(82,50 \%)$. Mais da metade dos alunos acredita que as práticas tiveram função educativa $(52,50 \%)$, seguida de motivacional $(12,50 \%)$.

Tabela 1 - Resultados da avaliação do minicurso pelos alunos do COLUN-UFMA.

\begin{tabular}{lccc}
\hline Critérios de avaliação & Sim $(\boldsymbol{\%})$ & Mais ou menos (\%) & Não (\%) \\
\hline Fácil aplicação & 93,75 & 0,00 & 6,25 \\
Interação com conteúdo & 75,00 & 25,00 & 0,00 \\
Metodologia de fácil entendimento & 93,75 & 6,25 & 0,00 \\
Aumentou motivação para aprendizado & 62,50 & 18,75 & 18,75 \\
Manutenção do minicurso na escola & 100,00 & 0,00 & 0,00 \\
\hline
\end{tabular}

\section{CONSIDERAÇÕES FINAIS}

As práticas realizadas utilizavam materiais baratos e objetos comuns no dia-adia dos alunos, demonstrando a viabilidade deste recurso para o ensino de ciências. Além disso, estas aulas práticas tiveram um efeito benéfico sobre o aprendizado dos alunos, contribuindo para compreensão da teoria das matérias de genética e bioquímica, o que foi demonstrado pela melhoria das respostas na avaliação final.

$\mathrm{O}$ efeito motivacional das práticas evidencia a importância das mesmas para o ensino, pois a sua contribuição para a construção de conhecimento é mais enfática que as clássicas aulas expositivas.

\section{REFERÊNCIAS BIBLIOGRÁFICAS}


BORGES, A.T. Novos rumos para o laboratório escolar de ciências. Caderno Brasileiro de Ensino de Física. Vol.19, n. 3, p.291-313, 2002.

BRASIL. Ministério da Educação, Secretaria de Educação Média e Tecnológica. Parâmetros Curriculares Nacionais: Ensino Médio. Brasília: Ministério da Educação, 1998.

BRASIL. Ministério da Educação, Secretaria de Educação Média e Tecnológica. Parâmetros Curriculares Nacionais: Ensino Médio. Brasília: Ministério da Educação, 1999.

CASAGRANDE, G. L. Clonagem e terapia gênica: as novas tecnologias aparecem no livro didático de Biologia. In: 4a SEPEX: Semana de Ensino, Pesquisa e Extensão da UFSC, 2004, Florianópolis. Anais da 4a SEPEX Disponível em:

http://www.sepex.ufsc.br/anais_4/index_fixo800600.html. Acesso em: 05 de dezembro de 2010.

CERRI, Y.L.N.S. \& TOMAZELLO, M.G.C. Crianças aprendem melhor ciências por meio da experimentação? Em: Pavão A.C. e Freitas, D. (Orgs). Quanta ciência há no ensino de ciências Editora UFSCar. São Carlos, 2008.

FALA, A. M.; CORREIA, E. M. \& PEREIRA, H. M. Atividades práticas no ensino médio: uma abordagem experimental para aulas de genética. Ciências \& Cognição. Vol. 15, n. 1, p. 137-154, 2010.

GIOPPO, C. ; SCHEFFER, E. W. O. \& NEVES, M. C. D. O Ensino experimental na Escola Fundamental: uma reflexão de caso no Paraná. Educar em Revista, Curitiba, v.14, n. 14, p. 39-57, 1998.

IZQUIERDO, M.; SANMARTÍ, N. \& ESPINET, M. Fundamentación y diseño de las prácticas escolares de ciencias experimentales. Enseñanza de las Ciencias Vol.17, n. 1, p. 45-60, 1999.

JUSTINA, L. A. D. \& RIPPEL, J. L. Ensino de Genética: Representações da Ciência da Hereditariedade no Nível Médio. In: IV Encontro Nacional de Pesquisa em Educação em Ciências, 2003, Bauru. Atas do Encontro Nacional de Pesquisa em Educação em Ciências. Bauru: ABRAPEC, 2003.

KRASILCHIK, M. \& MARANDINO, M. Ensino de Ciências e Cidadania. Editora Moderna. São Paulo, 2004.

LAKATOS, E. M. Metodologia do trabalho científico. $7^{\text {a }}$. Edição. São Paulo: Editora Atlas, 2001.

LEITE, A. C. S.; SILVA, P. A. B.; VAZ, A. C. R. A importância das aulas práticas para alunos jovens e adultos: uma abordagem investigativa sobre a percepção dos alunos do PROEF II. Revista da Faculdade de Educação da UFMG. Disponível em: http://www.portal.fae.ufmg.br/seer/index.php/ensaio/article/viewFile/98/147. Acesso em: 05 de dezembro de 2010. 
LUNETTA, V. N. Atividades práticas no ensino da ciência. Revista Portuguesa de Educação Vol. 2, n.1, p.81-90, 1991.

NUNES, F. M. F.; FERREIRA, K. S.; SILVA-JR, W. A.; BARBIERI, M. R. \& COVAS, D. T. Genética no Ensino Médio: uma prática que se constrói. Revista Genética na escola. Vol.1, n. 1, p. 19-24, 2006.

POSSOBOM, C. C. F. ; OKADA, F. K. \& DINIZ, R. E. S. As atividades práticas de laboratório no ensino de Biologia e Ciências: relato de uma experiência. Editora da UNESP. Vol. 1, p. 113-123, 2003. Disponível em:

<http://www.unesp.br/prograd/PDFNE2002/atividadespraticas.pdf $>$. Acesso em: $14 \mathrm{de}$ abril de 2011.

REIS, T. A.; ROCHA, L. S. S.; OLIVEIRA, L. P. \& LIMA, M. M. O. O ensino de genética e a atuação da mídia. Em: Anais do V Congresso de Pesquisa e Inovação da Rede Norte Nordeste de Educação Tecnológico, 2010.

SALM, C. A Escola e o Trabalho. Editora Cortez. São Paulo, 1985.

SONCINI, M. I. Biologia. Editora Cortez. São Paulo, 1991.

\section{ANEXO A}

\section{Questionário para a avaliação dos conhecimentos sobre genética e bioquímica}

1) O que são genes alelos?

2) O que é o DNA? Aonde este se localiza? Quais suas funções?

3) O que são as bases nitrogenadas?

4) O que é o RNA? Aonde este se localiza? Quais suas funções?

5) Como você definiria "gene"?

6) O que é o genoma?

7) Como você relacionaria o a sua definição de gene com conceito de fenótipo?

8) O que é e como ocorre o processo de transcrição?

9) O que é e como ocorre o processo de tradução?

10) O que você entender por "engenharia genética"?

11) O que seria polimorfismo?

12) O que são polissacarídeos? Aonde são encontrados?

13) O que são ligações peptídicas e qual a sua relação com a estrutura de proteínas?

14) O que é aglutinina? Qual sua relação com o sistema $A B O$ ?

15) O que é aglutinogênio? Qual sua relação com o sistema $A B O$ ? 


\section{ANEXO B}

\section{Questionário para a avaliação da metodologia empregada no minicurso}

1) Você acha que as aulas práticas realizadas são de fácil aplicação?
a. $\operatorname{Sim}$
b. Mais ou menos
c. Não

2) Você acha que as aulas práticas integraram o conteúdo teórico de genética?
a. $\operatorname{Sim}$
b. Mais ou menos
c. Não

3) Você acha que as metodologias empregadas foram de fácil entendimento?
a. $\operatorname{Sim}$
b. Mais ou menos
c. Não

4) Seja sincero: As práticas aumentaram sua motivação para o aprendizado de genética e bioquímica?
a. Sim
b. Mais ou menos
c. Não

5) Você acha que as práticas tiveram, pra você, a função:

a. Educativa b. Esclarecedora c. Lúdica d. Divertimento e. Motivacional

6) Você acha que o minicurso prático deve ser mantido como atividade da escola?
a. Sim
b. Mais ou menos
c. Não 